\title{
TEMPERATURES UNDER GLASS SLIDES USED IN MONITORING THE SEASONAL RELEASE OF APPLE BLACK SPOT ASCOSPORES
}

\author{
W.R. HENSHALL and R.M. BERESFORD
}

\begin{abstract}
The Horticulture and Food Research Institute of New Zealand Ltd., Mount Albert Research Centre, Private Bag 92 169, Auckland
\end{abstract}

\begin{abstract}
Temperatures were measured under two glass slides mounted over leaf litter under the canopy of an apple tree, configured as for monitoring Venturia inaequalis ascospore release. They were compared with temperatures on the surface of the adjacent litter, and in air $20 \mathrm{~cm}$ above ground. Temperatures under the slides were higher during the day than those on the adjacent surface, which in turn were higher than daytime air temperatures. However, comparison of accumulated temperatures under the slides with accumulated temperatures on the adjacent litter surface suggests that ascospores are unlikely to be released more than one or two days earlier under glass slides than in undisturbed leaf litter. Keywords: apple, ascospore release, black spot, temperature accumulation, Venturia inaequalis
\end{abstract}

\section{INTRODUCTION}

Efficient disease management of apple black spot in New Zealand requires detailed knowledge of the availability of ascospores of the black spot fungus, Venturia inaequalis, as well as host susceptibility and suitability of environmental conditions for infection. A method which has been developed for regional monitoring of ascospore release involves weekly counts of ascospores naturally discharged onto glass microscope slides from leaf litter, using a modification of Parham's (1932) method (Manktelow and Beresford 1995). Leaves colonized by V. inaequalis are collected in autumn from underneath diseased apple trees and are placed between layers of wire mesh, then overwintered in an orchard environment. In spring, glass microscope slides are clipped onto the wire mesh and changed weekly, allowing ascospore release to be monitored through microscope counts of ascospore numbers on the glass slides.

Since the rate of release of ascospores depends on temperature (Brook 1976; Gadoury and McHardy 1982; James and Sutton 1982), and since temperatures under the glass slides used for ascospore monitoring could be expected to exceed surrounding temperatures under sunny conditions, the question arises whether the glass slide method predicts natural ascospore release accurately. The purpose of this study was to compare temperatures under glass microscope slides with adjacent surface temperatures, and, using information on the temperature dependence of ascospore maturation, determine whether ascospore release estimated by the glass slide method was likely to occur earlier than in the surrounding leaf litter.

\section{METHOD}

Temperatures were measured with YSI 44005 thermistor probes, under the canopy of a five year old cv. Royal Gala apple tree in an experimental orchard at Mt. Albert Research Centre, Auckland. A probe was placed under each of two glass microscope slides clipped to wire mesh on the ground, approximately $0.5 \mathrm{~m}$ from the trunk of the tree, as in the ascospore monitoring technique (Manktelow and Beresford 1995). A third probe was threaded into the wire mesh approximately $5 \mathrm{~cm}$ from one of the slides. Although this probe was about $1 \mathrm{~mm}$ above the litter, it is referred to herein 
as on the litter surface. Air temperature was measured $20 \mathrm{~cm}$ above ground in a wooden radiation shield (Heine 1981). The probes under and adjacent to the glass slides were unshielded. Mean temperatures were recorded each hour by a LiCor LI-1000 data logger over the period 4 November to 18 December 1995.

\section{RESULTS AND DISCUSSION}

At night, temperatures recorded by all four probes were similar, while during daylight hours the temperatures under the slides were greater than those adjacent to the slides, which in turn were greater than those recorded by the shielded air temperature probe (Fig. 1). Accumulated temperatures $\left({ }^{\circ} \mathrm{C}\right.$ days above $0^{\circ} \mathrm{C}$ base) were used to investigate the possible effect of the higher temperatures under the glass slides on ascospore release, defined as a cumulative percentage of the total number of ascospores recorded for the season (Manktelow and Beresford 1995).

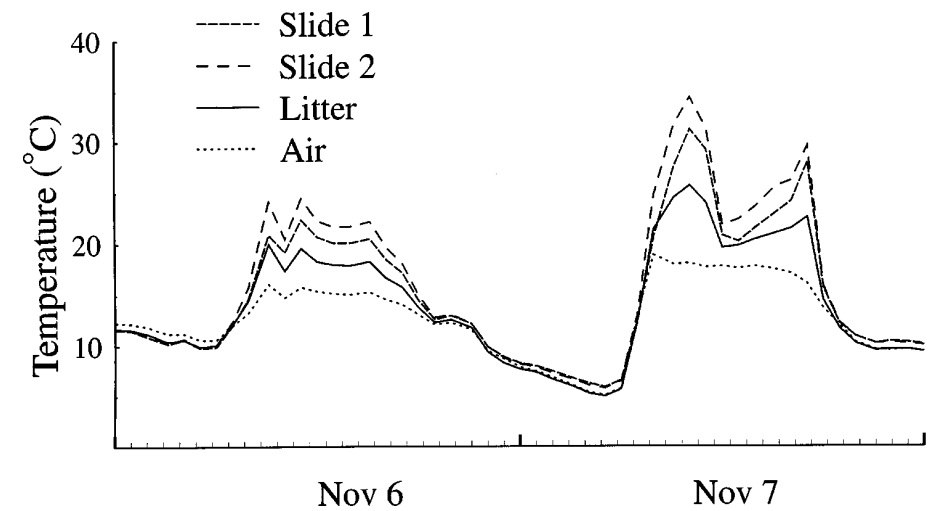

\section{FIGURE 1: Example of mean hourly temperatures under glass microscope slides, on adjacent leaf litter, and in air $20 \mathrm{~cm}$ above ground, over two days in November 1995.}

Fig. 2 illustrates the temperature accumulation over the measurement period. The probes under the glass slides took two and three days respectively less than the probe on the litter surface to reach $650{ }^{\circ} \mathrm{C}$ days, which was taken to be the temperature accumulation required for $1-95 \%$ ascospore release. These differences were small compared with the 36-39 days required to reach this temperature accumulation. The temperature difference between probes under the two glass slides, which was consistent throughout the measurement period, may have been due to differences in shading from the tree canopy. All probes were within $0.2^{\circ} \mathrm{C}$ of each other at calibration before measurements began. The shielded air temperature probe took two days longer than the probe on the litter surface to accumulate $650{ }^{\circ} \mathrm{C}$ days.

The choice of $650^{\circ} \mathrm{C}$ days as the required temperature accumulation was arrived at with difficulty because there is conflicting information in the literature. Gadoury and McHardy (1982) described a relationship between the period from 1-95\% ascospore release and cumulative temperature of $422^{\circ} \mathrm{C}$ days $\left(0^{\circ} \mathrm{C}\right.$ base $)$. Manktelow (1990) found that the time to 95\% ascospore release at Lincoln, New Zealand, was about $50 \%$ longer than would be predicted by the Gadoury and McHardy model. Schwabe et al. (1989) found $900^{\circ} \mathrm{C}$ days were required to $95 \%$ release in South Africa.

It was thus necessary to derive a relationship between ascospore release and temperature accumulation for the Mt. Albert site. Ascospore release data at Mt. Albert were available for 1993 and 1994 (Manktelow and Beresford 1995), but litter temperatures were not. Temperatures on leaf litter in the Mt. Albert apple block for 1993 and 1994 were therefore estimated from the Owairaka meteorological station 


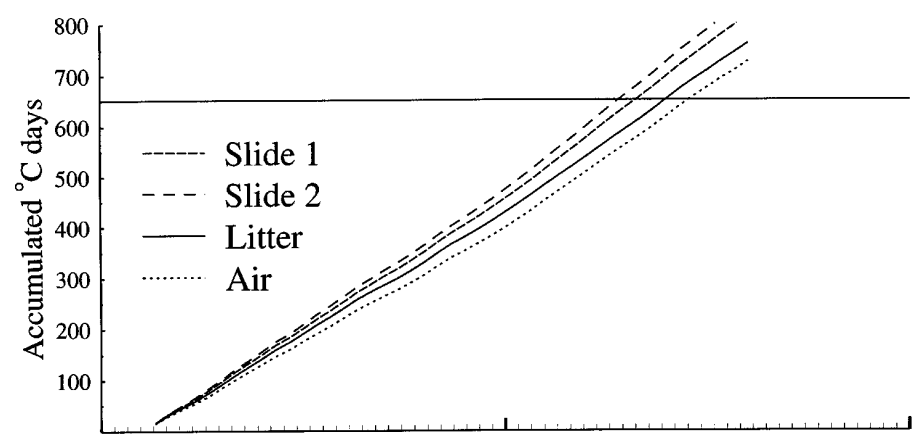

November

December

FIGURE 2: Degree day accumulation under glass microscope slides, on adjacent leaf litter, and in air $20 \mathrm{~cm}$ above ground in November and December 1995. The horizontal line at 650 degree days represents the temperature accumulation for $95 \%$ ascospore release.

daily screen temperatures, using a relationship between the 1995 leaf litter temperatures from this study and concurrent Owairaka data $250 \mathrm{~m}$ distant.

Temperature accumulations for $0.1-95 \%$ release were 840 degree days (1993) and 818 degree days (1994), and for 1-95\% were 662 (1993) and 645 (1994) ${ }^{\circ} \mathrm{C}$ days. It can be seen from the differences in accumulated temperature corresponding to 0.1 $95 \%$ and $1-95 \%$ release that the accumulated temperature value is very dependent on the starting time. This dependence probably accounts for some of the differences found in the literature. For the present study the $1-95 \%$ ascospore release range was chosen for consistency with Gadoury and McHardy (1982), requiring a temperature accumulation of $650{ }^{\circ} \mathrm{C}$ days (Fig. 2), a value consistent with Manktelow (1990).

A further analysis was made to investigate whether the peak temperatures under the glass slides in the middle of the day, which could be greater than $30^{\circ} \mathrm{C}$ (Fig. 1), might have a greater effect on ascospore release than the small effect suggested by the above analysis of daily mean temperatures (range 5-20 $\mathrm{C}$ ). The relationship between ascospore release and temperature of Gadoury and McHardy (1982) is based on laboratory experiments between 6 and $20^{\circ} \mathrm{C}$, with no information for higher temperatures. Many biological processes associated with plant pathogenic fungi exhibit an optimum temperature above which the development rate decreases. James and Sutton (1982) found the optimal temperature range for ascospore release to be 16$18^{\circ} \mathrm{C}$, with pseudothecia aborting after two weeks exposure to temperatures around $30^{\circ} \mathrm{C}$. While ascospore maturation may not be curtailed by a few hours exposure to high temperatures, it is likely that development is inhibited compared with the optimum rate.

In the present study, a nonlinear model of ascospore development, based on the above information, was applied to hourly data collected over the measurement period. In the model (Fig. 3) it was assumed that the development rate increased from zero to $.0308 /$ day over the temperature range $0-20^{\circ} \mathrm{C}$. The slope of the rate curve over this range corresponds to a temperature accumulation from $1-95 \%$ release of $650^{\circ} \mathrm{C}$ days. Above $20^{\circ} \mathrm{C}$ a constant development rate of .0308 /day was assumed to a temperature limit $\mathrm{L}_{1}$, then the development rate was assumed to decline linearly to zero at a second temperature limit $\mathrm{L}_{2}$.

The results of applying this model with limits $\mathrm{L}_{1}=22, \mathrm{~L}_{2}=30$ and $\mathrm{L}_{1}=25, \mathrm{~L}_{2}=35^{\circ} \mathrm{C}$ are shown in Fig. 4. The effects of higher temperatures under the glass slides, compared with the litter surface, were again minimal. In Fig. 4A, the predicted time to $95 \%$ ascospore release under Slide 1 is the same as on the litter surface, and under 


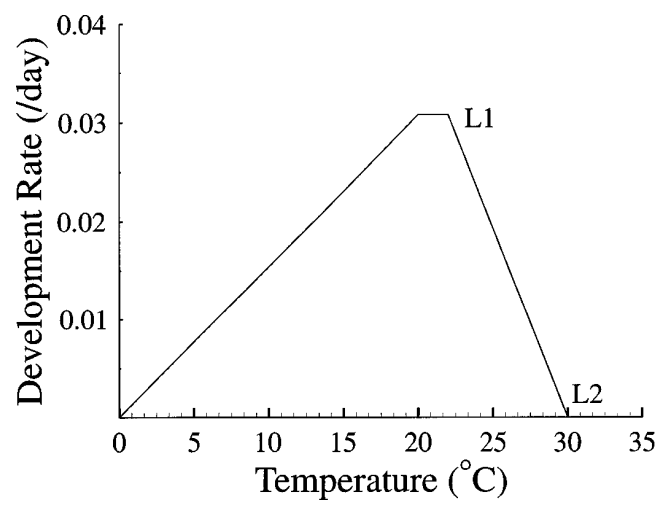

FIGURE 3: Nonlinear model of rate of development of mature ascospores. The slope between 0 and $20^{\circ} \mathrm{C}$ corresponds to 650 degree days from $1 \%$ to $95 \%$ ascospore release. $L_{1}$ and $L_{2}$ are variable temperature limits.
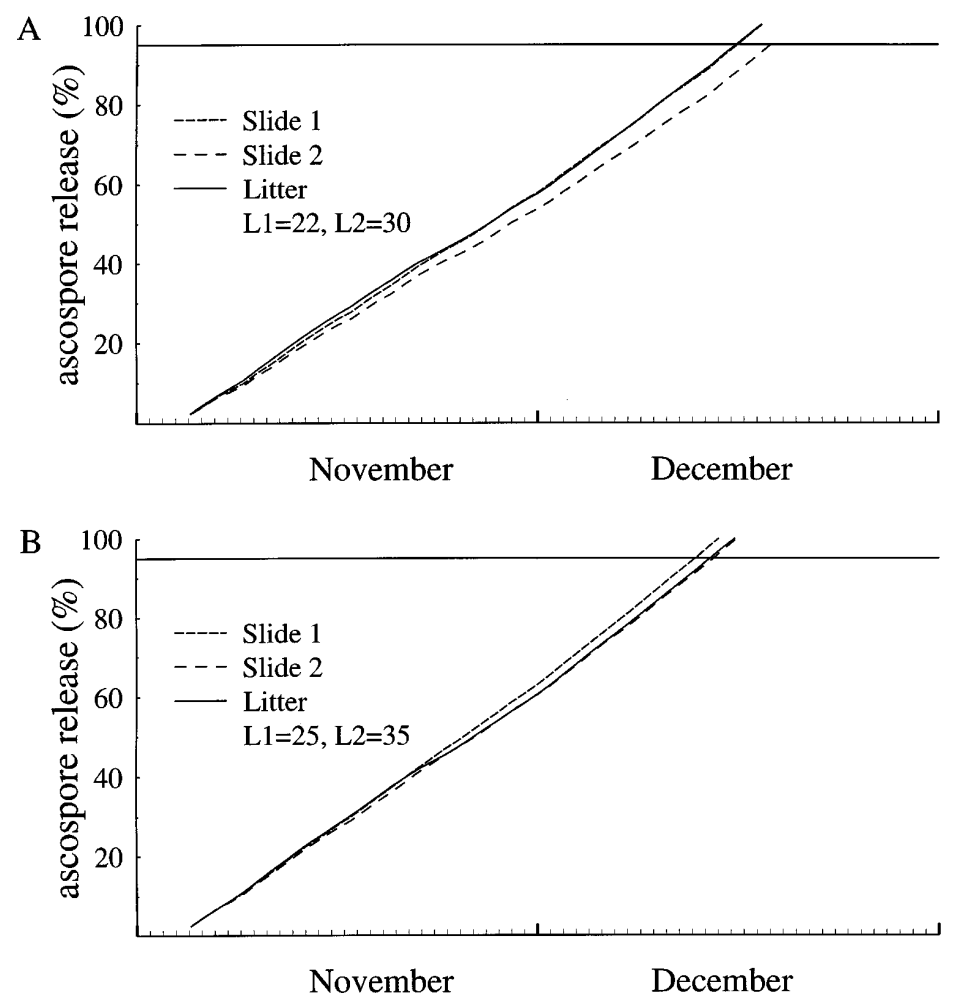

FIGURE 4: Acospore release predicted by the nonlinear model. A. Parameters $\mathrm{L} 1$ and $\mathrm{L} 2$ (Fig. 3), 22 and $30^{\circ} \mathrm{C}$ respectively; B. L1 and L2, 25 and $35^{\circ} \mathrm{C}$ respectively. 
Slide 2 is three days longer than on the litter surface. In Fig. 4B, the predicted time to $95 \%$ ascospore release under Slide 1 is one day less than on the litter surface, while under Slide 2 is the same as on the litter surface. Overall the difference between ascospore release times under the slides compared with that on the litter surface was less than for the analysis which considered mean daily temperatures only. The reduced rate under the glass slides during the highest daytime temperatures appeared to be offset by the increased rate from higher under-glass temperatures in the sub-optimum to optimum range during other times of day.

This study has considered the effect of temperature on ascospore release, but moisture also affects spore release (Brook 1976). It is possible that glass slides modify the moisture in the leaf litter underneath, with consequences not addressed here.

\section{CONCLUSION}

Although temperatures under glass slides used in monitoring the release of apple black spot ascospores are at times higher than those on the surrounding leaf litter, the effectiveness of the glass slide method for monitoring ascospore release is unlikely to be adversely affected. Assumptions of a nonlinear relationship between ascospore development and temperature indicate that a reduced rate of maturation at temperatures around $30^{\circ} \mathrm{C}$ can compensate for an enhanced maturation rate arising from a greater number of hours near the optimum temperature. Differences in the temperature accumulation required for $95 \%$ ascospore release reported in the literature could be due to inconsistent definitions for the start of ascospore release.

\section{ACKNOWLEDGEMENTS}

The authors thank David Manktelow for the original hypothesis that higher temperatures under glass slides might speed ascospore release, and the Foundation for Research, Science and Technology for funding this study.

\section{REFERENCES}

Brook, P.J., 1976. Seasonal pattern of maturation of Venturia inaequalis ascospores in New Zealand. N.Z. J. Agric. Res. 19: 103-109.

Gadoury, D.M. and McHardy, W.E., 1982. A model to estimate the maturity of ascospores of Venturia inaequalis. Phytopath. 72: 901-904.

Heine, R.W., 1981. Weather and your garden. New Zealand Meteorological Service Miscellaneous Publication 168.

James, J.R. and Sutton, T.B., 1982. Environmental factors influencing pseudothecial development and ascospore maturation of Venturia inaequalis. Phytopath. 72: 1073-1080.

Manktelow, D.W.L., 1990. A systems approach to apple black spot control in Canterbury. M.Hort.Sc. Thesis, Lincoln University, New Zealand.

Manktelow, D.W.L. and Beresford, R.M., 1995. Evaluation of an ascospore monitoring method forVenturia inaequalis to improve apple black spot fungicide management. Proc. 48th N.Z. Plant Prot. Conf.: 78-82.

Schwabe, W.F.S., Jones, A.L. and van Blerk, E., 1989. Relation of degree-day accumulations to maturation of ascospores of Venturia inaequalis in South Africa. Phytophylactica 21: 13-16. 